\title{
Intraoperative Hemorrhage
}

National Cancer Institute

\section{Source}

National Cancer Institute. Intraoperative Hemorrhage. NCI Thesaurus. Code C35135.

Uncontrolled bleeding during a surgical procedure. 